Please send trade news information and

illustrations to Arveen Bajaj at the BDJ, Nature

Publishing Group, The Macmillan Building,

4-6 Crinan Street, London N1 9XW.

Trade news is provided as a service to readers

using text and images from the manufacturer,

supplier or distributor and does not imply

endorsement by the BDJ. Normal and prudent

research should be exercised before purchase or

use of any product mentioned.

\section{Dental practice call recognition}

'Can I say who's calling?' is a common response when calling many businesses. Such questions could soon be answered automatically with Software of Excellence's Exact CTI module.

CTI, or Computer Telephony Integration has several features, but the most exciting for a dental practice is call recognition. As the phone rings in the practice, the computer reads the incoming telephone number and uses this to identify the patient's record.

Your staff can see who is calling and key information about the caller; for example the balance of their account, treatment plans, outstanding and failed appointment history and notes about previous conversations. So now you can greet your patients by name and know

\section{Diamond polishing system}

The Two Striper Cerec 3D Prep \& Polish Diamond Rotary Kit from Premier Dental Products contains seven Two Striper diamonds in an autoclaveable bur block and Luminescence Plus diamond polishing system.

These Two Striper diamonds have been specifically selected to create welldefined anatomy and readable preps. They are made with a patented bonding system that features a greater concentration of diamond particles and significantly lower bond height than electroplated brands. More cutting sur-

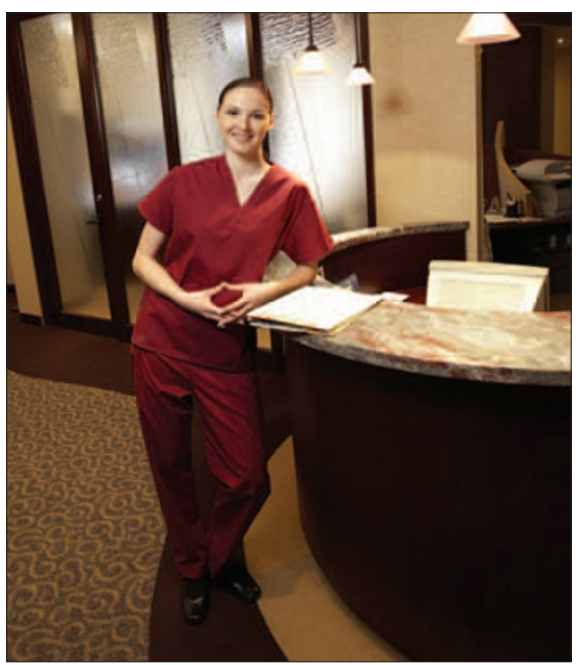

exactly how to deal with them. Practices can also benefit from the call reporting function. Both inbound and outbound calls can be audited and tracked.

Reader response number 50

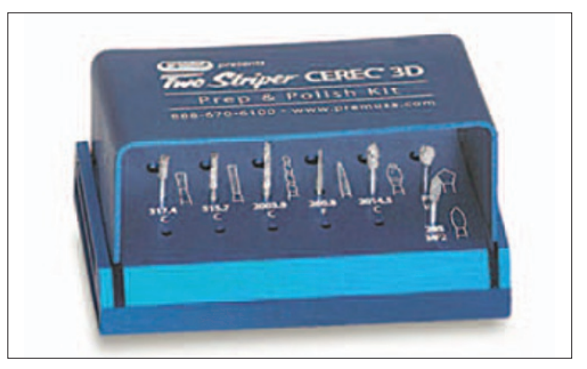

faces of the natural diamond crystals are exposed for fast, controlled tooth preparation and material adjustment.

The diamond shapes include TS2000 Speed Cut spirals and assorted other shapes for Cerec tooth preparations as well as finishing and polishing procedures.

Reader response number 51

\section{Let patients see caries}

You can now clearly show patients the prevalence of decay with the aid of VistaProof from Dürr Dental, a fluorescence camera capable of detecting caries quickly and accurately. Caries is shown even in fissures and on occluded surfaces, where to the naked eye or on X-ray photographs it may be hard or impossible to detect.

It is as fast as a mirror examination and the high performance software displays a false colour image on which active caries appears in red and healthy enamel in green. In contrast to other screening systems, it also shows caries that was not previously diagnosed so that it can be used to monitor the progression of caries conditions over a period of time (the fluorescence images can be conveniently stored with the powerful software in a patients' database). It also has a function as a patient motivation and communication tool, since it can be used to promote better oral hygiene.

Reader response number 52

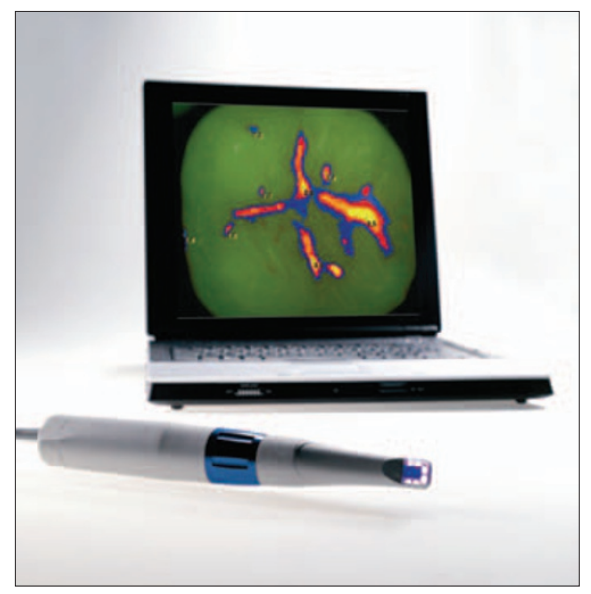

\section{Seat re-covering service available}

Bambach Europe Ltd is offering a re-covering service for its saddle seats that are more than five years old. You may find that the colour scheme in your practice has changed during this time or that the cover is simply showing signs of wear and tear. The Bambach Saddle Seat helps to align the spine whilst maintaining the natural s-shape, thus preventing the discs from being put under pressure.

The hips are kept at the optimum angle of $45^{\circ}$ to the spine so back and thigh muscles are at their most relaxed. Each Bambach Saddle Seat is fully adjustable to create a bespoke stool for each individual.

The company offer a 30-day trial for new users. Please contact Bambach directly to arrange re-covering of your seat.

Reader response number 53 


\section{PRIVATE PRACTICE}

\section{Specialist lenders}

The Loan Hunter - a specialist dental loan broker - is expert in the world of commercial finance, sourcing the best deals available for you with the lowest interest rate at no cost.

Whether you want a loan for practice purchase and practice development, or just to exploit lower interest rates, Loan Hunter uses specialist lenders together with its transparent way of working, giving you access to expert bankers without any catches, charges or tie-ins.

It can arrange unsecured loans and as part of the Loan Hunter suite of serv-

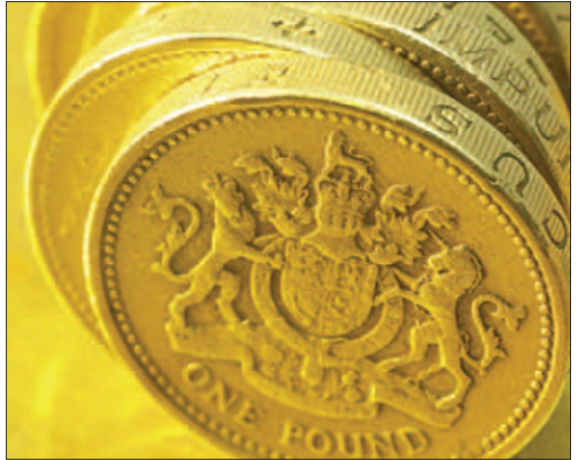

ices, can discuss debt consolidation or improving the terms of an existing loan. Reader response number 54

\section{Regain control}

Your practice could be entitled to offset expenses such as the cost of equipment, consumables and even the electricity bill, against your income, making savings which could then be invested back into the business, according to money4dentists.

It claims that many dentists neglect to claim tax relief on a huge range of qualifying expenses.

Money4dentists is able to offer advice and money-saving financial guidance to the dental profession.

Reader response number 55 


\section{High quality implant treatments}

3dee Loans allows you to offer all of your patients the highest quality implant treatments that many of them cannot afford. The anxiety of possibly not being paid and the concerns about the patient agreeing to a treatment beyond their means are relieved.

3dee enables patients to spread the cost of their dental treatment, up to as much as $£ 25,000$ for more extensive treatment, over an agreed period of up to five years. The loans minimise the risk to the practice, offer competitive

\section{Clinical audit package}

Smile-on, in collaboration with Denplan, offers a comprehensive effective clinical audit package which provides advice and practical support to help audit and review your practice's performance.

An effective audit is important in every practice as a positive exercise to guide you through a process of continual improvement. The audit package

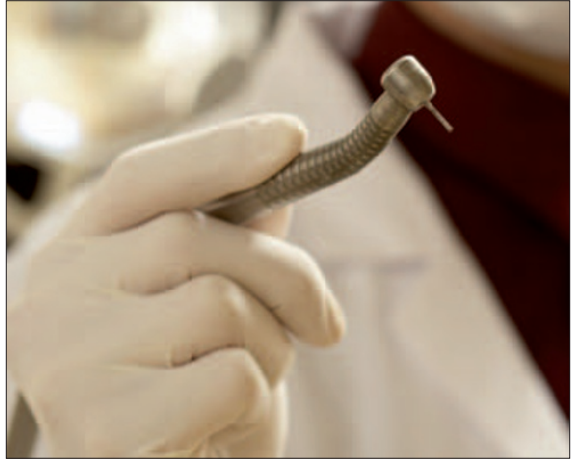

\section{Establishing your own practice}

Frank Taylor \&t Associates (FTA) are specialists in the sale of dental practices and have wide experience in every aspect of this specialised market. FTA maintains a register of dentists seeking to establish their own practice and can match prospective purchasers with their ideal practice.

In many cases discretion is paramount, interest rates and an interest free option, increase profits and deliver immediate, upfront payment.

Reader response number 56

offers an overview of the audit process, with explanatory notes and guidance and practical tools you can use when conducting your audit.

Available on CD-ROM or online, with a comprehensive booklet, you are guided step-by-step through eight different audit areas including quality of radiographs, patient waiting times, periodontal record keeping and emergency appointments.

Reader response number 57 and FTA has procedures in place to market the practice to only serious candidates with access to adequate finance, eliminating voyeurs with no intention of proceeding.

The company's experience enables accurate valuations and competent and comprehensive negotiations with all interested parties to create a smooth progression to a satisfactory conclusion.

The FTA is able to relieve much of the anxiety inherent in a practice transfer for both buyers and sellers through its established associations with specialist, reputable legal advisers and sources of finance.

Reader response number 58 